\title{
Kierkegaard y el matrimonio
}

\author{
RODRIGO FIGUEROA WEITZMAN \\ Universidad Andrés Bello (Chile) \\ rfigueroa@unab.cl
}

\begin{abstract}
Resumen
Este artículo considera dos perspectivas de Kierkegaard en relación con el matrimonio, una en favor y otra en contra del mismo. El texto se centra en los principales argumentos del filósofo danés en torno a los motivos para elegir el estado conyugal (entre otros, la procreación de los hijos y la evasión de la soledad) como a las razones que induzcan a alguien a permanecer definitivamente soltero (por ejemplo, si tiene una vocación religiosa o si no quiere perder su libertad). El artículo presenta también otras dos ideas importantes del pensador escandinavo sobre la institución matrimonial: su origen divino y la relación entre el amor y el vínculo nupcial.
\end{abstract}

Palabras clave: matrimonio, soltería, hombre, mujer, hijo, carácter.

\section{Kierkegaard and the marriage}

\begin{abstract}
This article focuses on two perspectives of Kierkegaard regarding marriage, one in favour and one against it. Te text concentrates on the principal arguments of the danish philosopher about the choice for marriage (some reasons are the procreation of children and escaping from solitude) as the election of the reasons that may lead somebody to remain single (for example, if someone has a religious calling or if someone prefers to continue without losing their freedom). The text also presents other two ideas of this philosopher over the marriage institution: his divine origin and the relationship between love and the bond of matrimony.
\end{abstract}

Key words: marriage, single, man, woman, children, character.

Doctor en Filosofía (Pontificia Universidad Católica de Chile). Profesor Departamento de Humanidades de la UNAB. Ha publicado el libro de crónicas titulado De la fuga a la espera: esbozos de un alegre melancólico (2008), y algunos artículos como "Olvido, memoria y esperanza en Jean-Louis Chrétien" (2008), "Dios, el mal y el sufrimiento en Simone Weil" (2009), y "Kierkegaard y una preocupación pagana” (2010). 
«Hace falta valor para casarse», sostuvo Søren Kierkegaard (1955: 91) en su Diario intimo. Quizás él mismo careció de esa valentía y por ello nunca se casó. Sin embargo, no fue esa su única razón para permanecer soltero. La lectura del mismo diario ya mencionado da a entender otras importantes motivaciones. Por una parte, parece ser que no quiso contraer matrimonio con Regina Olsen, la mujer que amaba, a causa de su deseo de no transmitirle su melancolía:

De no haber sido un penitente, de no haber tenido mi vida ante acta, de no ser melancólico, la unión con ella me habría proporcionado una felicidad como nunca la soñara (Kierkegaard, 1955: 382).

Kierkegaard no sólo se consideraba demasiado viejo para Regina — le llevaba diez años de diferencia—, sino a su vez se sentía «abrumado, por añadidura, con una melancolía que presentaba todas las trazas de la fatalidad» (Jolivet, 1950: 42). Se veía a sí mismo, a fin de cuentas, prisionero de ese rasgo de su personalidad, característica que al mismo tiempo vetaba para él cualquier posibilidad de casarse. Llegará incluso al extremo de llamar a su propia melancolía «la más fiel amante que he conocido» (Kierkegaard, 1999: 54). Por otra parte, Kierkegaard estaba convencido de que la religión —el cristianismo en particular- requería de hombres célibes:

La cristiandad tenía verdadera y suma necesidad de una persona célibe que tomara en sus manos la causa del cristianismo. No es que tenga que objetar nada contra el matrimonio, pero ha cobrado demasiada importancia... Tienes permiso para casarte y el cristianismo bendice tu matrimonio, pero no olvides que has de dejar lugar a las existencias religiosas más decisivas. De otra manera se podría reprochar a San Pablo que no fuera casado (Kierkegaard, 1955: 238).

Sea como sea, y a pesar de su soltería, que quizás podemos catalogar de voluntaria, en algunos pasajes Kierkegaard duda respecto a si hizo bien permaneciendo soltero. No le era evidente haber hecho lo correcto no casándose con Regina: «Si hubiera tenido fe no me habría separado de Regina: ahora lo comprendo» (Kierkegaard, 1955: 113).

Habiendo señalado lo anterior a modo de preámbulo, nos cabe decir que las reflexiones de Kierkegaard en torno al estado conyugal se refieren al mismo tanto en términos favorables como desfavorables. Veamos, entonces, sus ideas en un sentido y en otro. 


\section{Razones para casarse}

;Alabado sea el matrimonio, alabado sea todo el que hable en su honor! (Kierkegaard, 1951b: 103).

Consideremos primero las razones que ‘justifican’ por qué los seres humanos, al menos en muchos casos, deben optar por convertirse en esposos:

El cristianismo dice: 'No te cases, ésta es la conducta agradable a Dios y la más lógica si tú eres verdaderamente cristiano’. A esto el género humano responde: 'Pero si todos proceden así, la humanidad se extinguiría'. Y la hipótesis de que el género humano pueda desaparecer es considerada por la humanidad como la desgracia mayor. Entonces, en consecuencia, uno no puede menos que casarse; y hay una razón más para casarse: jla tremenda razón de que el género humano no debe desaparecer! He aquí otra razón más para casarse (Kierkegaard, 1955: 438).

La propagación de la especie humana, por ende, es para el filósofo de Copenhague un poderoso argumento en favor del estado conyugal. En Estética del matrimonio, Kierkegaard deja entrever el escaso aporte social de quien no tiene hijos. Por lo tanto, «casarse para contribuir a la propagación de la especie podría parecer una razón eminentemente objetiva y natural» (Kierkegaard, 1991: 64). Más aún si, a su juicio, los niños son auténticos maestros, en cuanto enseñan al poseer una espontaneidad ante la que no valen los principios y máximas abstractas. No se puede, por tanto, prescindir de este deseo natural de tener hijos: «Los hijos pertenecen al santuario de la familia, a su vida más recóndita, y es a ese claroscuro misterioso al que debe dirigirse todo pensamiento de gravedad y de piedad en esta cuestión» (Kierkegaard, 1991: 66).

Puede resultar curioso que un soltero sea tan taxativo en su reflexión en favor del matrimonio, pero no lo es en el caso de Kierkegaard que, si bien fue un gran solitario $y$ un temperamento excesivamente introvertido, da la impresión de haber comprendido bastante bien la esencia del vínculo matrimonial y el propósito incluso moral de éste: «es decisivo para todo concepto religioso de la vida, para toda religión, el modo de considerar al matrimonio, en virtud del cual entiendo yo la expresión ética de la propagación de la especie» (Kierkegaard, 1955: 412).

A nuestro entender, en estas líneas está la idea de que quien se casa da cabida al modo ético de propagar la especie humana y, por consiguiente, cabe suponer que la fortaleza del matrimonio se manifiesta en su eticidad. Engendrar hijos no es, por cierto, el único motivo para 
casarse. Sin embargo, es una causa relevante para hacerlo. De alguna manera, el orden de una sociedad queda mejor resguardado con el reconocimiento del matrimonio y de los hijos que se engendran dentro de éste. La especie humana tiene por misión propagarse y no desaparecer. Si bien podemos suponer que Kierkegaard, al igual que cualquiera, sabía perfectamente que no todo hijo es fruto del matrimonio y que no todo matrimonio necesariamente engendra un hijo, veía al estado nupcial como el espacio natural y más adecuado para esa multiplicación. Quizás por esta misma razón escribe que «por la ética es el matrimonio la expresión estética del amor» (Kierkegaard, 1950: 193). Si la procreación es un deber para el ser humano (sin procreación ninguno de nosotros sería), es claro que esa misión se cumple de un modo ordenadamente ético a través del matrimonio.

Sin embargo, a la luz de otros pasajes del Kierkegaard, lo dicho en el párrafo anterior, aunque sea efectivo, requiere de ciertas precisiones. En su Estética del matrimonio, nuestro pensador señala que casarse con la sola intención de traer hijos al mundo es arbitrario y poco natural, ya que Dios también instituyó el matrimonio porque no era bueno para el hombre estar solo y, por ello, le dio a la mujer como compañera. En su singular modo de ser, nuestro filósofo en cuestión dará incluso gracias a Dios «Porque ningún ser humano me debe su existencia» (Kierkegaard, 1955: 446). Bajo la óptica de Kierkegaard, entonces, existen más razones para casarse, dos de las cuales son también sumamente importantes: «escapan» de la soledad y «afirmar» el carácter. Revisemos someramente estos dos nuevos motivos planteados por el filósofo escandinavo.

En cuanto a casarse para evadir la soledad, Kierkegaard apunta la siguiente idea: «No es raro —dice él- que las personas casadas hablen de su propio consuelo y del tormento de los solteros: 'Tenemos nuestro techo, y cuando seamos viejos, un refugio'. Y a veces agregan con el énfasis solemne del sermón dominical: 'Nuestros hijos y nietos nos cerrarán los ojos y nos llorarán’» (Kierkegaard, 1991: 70). Estas palabras nos dan a entender que, según su visión, lo común a todos los casados es tener a alguien que llore su muerte y que los entierre. A quienes no se casan, en cambio les espera más bien la suerte opuesta, la de no tener a nadie que le cierre los ojos, la de quedarse sin una compañía indispensable para la vida. A la vida del soltero le falta el cobijo que al hombre casado se le da naturalmente en su estado. El soltero carece de hogar y de todas las alegrías y confianza en sí que suele traer consigo el estado matrimonial. Si vivimos solos nadie nos aguarda cuando estamos ausentes. En la perspectiva del filósofo danés, hay una contraposición entre el matrimonio y la soltería. Se puede decir que en el matrimonio cada uno 
es todo para el otro. Mientras que al soltero le acontece lo contrario: ha dado incluso todo a un sinnúmero de gente para la que realmente no ha sido nada. No tener a quien amar es tan triste y frustrante como no ser amado por alguien. Quien está solo experimenta la pobreza de quien vive únicamente para sí mismo. El soltero es como «un hambriento al que los alimentos le redoblan su hambre; un hombre atormentado por la sed, que la bebida no hace sino excitar aún más» (Kierkegaard, 1991: 78). Pese a este 'reproche' - expresión nuestra- que Kierkegaard parece referir a la condición de soltero, ve, sin embargo, un defecto común en todos los matrimonios que se contraen con el afán de huir de la soledad: hacer de un momento particular de la unión el motivo de esa unión. Esta última idea, según nuestro parecer, cabe entenderla como una crítica a considerar el deseo de no quedarse solo en la vida - un momento particular - como una razón suficiente para casarse. Para Kierkegaard sería erróneo casarse con este propósito. Querer evitar la soledad no es un argumento especialmente bueno para resolverse en favor del matrimonio (aunque bajo nuestra propia perspectiva tampoco sea un motivo a descartar de plano).

En líneas precedentes ya mencionamos que, según el pensador danés, otra razón para casarse es fortalecer el carácter. Sus palabras al respecto son claras:

...el matrimonio es una escuela del carácter... Hace madurar al alma, otorga un sentimiento de dignidad personal y también de pesada responsabilidad, que no se puede disipar porque uno ama de veras. Ennoblece todo el ser con el pudor propio de la mujer; ese pudor disciplina al esposo, porque la mujer es la conciencia del hombre. Vuelve armónicos los movimientos excéntricos del marido, y otorga a la vida apacible de la esposa fuerza y virtud, pero sólo en la medida que ella busque esa fuerza en su marido, y evite asi de convertirse en marimacho. Las bruscas cóleras del hombre se aplacan cuando vuelve constantemente a su compañera, y la debilidad de ella se fortifica cuando se apoya sobre él (Kierkegaard, 1991: 59-61).

En consecuencia, es lo que parece desprender de esta cita, la vida matrimonial forja la reciedumbre del hombre, puesto que lo inclina a una vida más responsable y le ayuda a dejar atrás la disipación propia de su condición de soltero. La ansiedad carnal, por decirlo así, se apacigua y se regula en el enlace esponsal. A su vez, el estado conyugal concilia adecuadamente la necesaria dulcificación del varón y el necesario robustecimiento de la mujer (en un justo equilibrio, claro está, sin que ninguno de los dos pierda las cualidades propias de su sexo). Nos da la 
impresión de que en la concepción kierkegaardiana el matrimonio ordena la vida sexual y social de los casados ('social' lo añadimos nosotros).

No obstante que en ciertos momentos de su vida tuvo un gran deseo de llegar a esta condición, Kierkegaard se sentía lejos del matrimonio: «Siendo poeta, no puede volver a bajar al reinado terrenal del matrimonio. No puede transformar la relación poética en una religión real. Aquella a quien ama, no es más que la encarnación del deseo que la trasciende» (Wahl, 1956: 13-14). Temía, así se desprende de la lectura de algunos pasajes de sus obras, que el matrimonio le separase de una existencia religiosa, la misma en que se alcanza lo eterno renunciando a lo temporal (y de los asuntos temporales, el matrimonio es uno de los más significativos). Pese a esta distancia real que siente respecto a casarse, habrá instantes en que, situándose en el papel de un esposo — papel que no cumplió-, agradecerá a Dios que su mujer sea su primer y único amor, y pedirá tener la fortaleza de no anhelar nunca ningún otro amor. Asumiendo el papel de marido considerará que todos los sentimientos, incluidos los religiosos, son más llevaderos y se ennoblecen cuando se comparten con la propia mujer.

En varios pasajes de sus escritos, el filósofo de Copenhague pronunciará palabras de elogio a este vínculo, incluso tomando para sí la condición de casado:

Lo que yo soy por mi mujer, ella lo es por mí, y ninguno de nosotros es algo por sí mismo sino solamente por alianza. Por ella yo soy un hombre verdadero; cualquier otro título no es nada en comparación, e implica realmente, éste; por ella soy padre, y cualquier otro honor no es más que una invención humana, una novedad que será olvidada dentro de cien años; por ella soy cabeza de familia, por ella soy el defensor de la casa, su sostén, el apoyo de los hijos (Kierkegaard, 1951b: 100).

También el matrimonio favorece mucho la naturaleza de la mujer. Una mujer casada alcanza un ornamento - la expresión es nuestra- que no suele darse en la condición de la mujer soltera. Dice Kierkegaard lo siguiente:

En mis reflexiones, me pregunto a menudo en qué instante puede parecer más seductora una muchacha... Creo que nunca es tan seductora como en el día de la boda. Cuando la muchacha se ha puesto ya su vestido de esponsales y el esplendor de la ropa palidece ante el esplendor de su belleza y ella misma se muestra pálida; cuando en ella se detiene la sangre, el pecho permanece inmóvil, la mirada se torna insegura, el pie titubea, la virgen tiembla, el fruto madura; cuando el cielo la levanta, la seriedad la robustece, 
la promesa la sostiene, el ruego la bendice, el mirto la corona; cuando el corazón palpita y ella abate la vista al suelo y se oculta a sí misma; cuando su pecho se ensancha en el suspiro, la voz languidece, la lágrima tiembla; cuando el enigma está por resolverse y la antorcha por encenderse; cuando el esposo ya espera, ese instante es aquel en que la muchacha está más seductora (Kierkegaard, 1973: 132-133).

Es decir, si hay un día en que la mujer resalta en su máximo esplendor, ese día a ojos de Kierkegaard no es otro que el día en que ella se viste de belleza y de alegría porque le ha llegado el momento de casarse, un momento sumamente esperado por ella.

Antes de cerrar este apartado, y habiendo considerado tres razones que Kierkegaard establece como las causas principales y más comunes que apoyan la condición matrimonial, queremos considerar dos aspectos más en los que el pensador de Copenhague se detiene en relación con la condición de casado: el origen divino del enlace matrimonial y su relación con el amor. Fijémonos brevemente en estos dos sellos del vínculo marital.

\section{a) Origen divino del matrimonio}

Estimamos importante en nuestra reflexión ahondar en el vínculo que Kierkegaard ve entre el estado nupcial y lo religioso. Dicho de otro modo, buscamos mostrar cuáles son las razones que el filósofo señala en torno a este lazo existente entre una realidad humana con un origen propiamente divino.

En un pasaje de su diario Kierkegaard argumenta que la presencia de Cristo en la boda de Caná (Jn 2,1-12) no indica nada particular en relación con el matrimonio, ya que como Maestro iba a todas partes, «dispuesto a buscar la oportunidad de enseñar» (Kierkegaard, 1955: 328). Si Cristo fue al matrimonio habría ido por razones pedagógicas antes que afectivas o familiares. Todavía más, Kierkegaard piensa que la madre de Jesús tuvo que forzarlo a hacer el milagro de convertir el agua en vino, puesto que él no se mostraba muy dispuesto a intervenir:

...el matrimonio se vincula con el cristianismo como María con el milagro; en el fondo, el cristianismo no quiere mezclarse en ese asunto; se mantiene indiferente, sea que te cases o no te cases. Pero la mujer ruega para que así sea, y entonces el cristianismo cede y por un momento concuerda con la idea de la mujer sobre el matrimonio (Kierkegaard, 1955: 329). 
No obstante estas consideraciones acerca de la participación de Cristo en un matrimonio en Caná de Galilea, también hallamos en Kierkegaard la idea de que hay una génesis religiosa del mismo. El matrimonio es de origen divino y no humano y, por lo tanto, romperlo es oponerse a Dios:

...pero el matrimonio es, sin reserva, de origen religioso. Por eso el que lo rompe, no solamente se agobia a sí mismo de miserias así como a los que ama, sino que pone a la existencia en contradicción consigo misma, pone a Dios en contradicción consigo mismo (Kierkegaard, 1951b: 186).

A nuestro entender, es importante resaltar esta última idea de Kierkegaard. De acuerdo a sus expresiones, no cabe suponer para el matrimonio un origen distinto al divino. El matrimonio, es su tesis, viene de Dios y no de los hombres. Es, por consiguiente, un estado grato a Dios. Su génesis no es humana y, por ende, no la está permitido al hombre socavar aquello cuyo inicio está en Dios. Al ser humano le está prohibido, entonces, romper un compromiso cuyo fundamento es sagrado por provenir de Dios:

Nunca la mujer ha formulado objeciones al matrimonio, y nunca, nunca se le ocurriría hacerlo si los hombres no la corrompieran, porque sólo una mujer emancipada podría tener ideas semejantes. El escándalo proviene siempre del sexo fuerte, porque el hombre es orgulloso, quiere serlo todo, y no quiere que exista nada por encima de él (Kierkegaard, 1991: 50).

Para Kierkegaard, hay una mayor voluntad de la mujer en relación con la decisión de casarse. Hay en ella un mayor querer y deseo de unirse a un hombre en el estado conyugal.

Por ello, tal parece decir en el párrafo anterior, no cabe quebrantar lo que se contrajo ante Dios. Quien se casa ante Dios se obliga de por vida. Kierkegaard piensa que la disolución del vínculo matrimonial se da cuando el hombre considera que ese lazo es simplemente humano y se permite a sí mismo ponerle fin. Pero si no se diese a sí mismo ese permiso las dificultades matrimoniales se zanjarían más fácilmente. Kierkegaard es tajante en cuanto a la necesidad de que los casados no tengan opciones de revertir su decisión:

La razón por la cual el vínculo matrimonial se vuelve insoportable para aquellos que quieren separarse, se debe al hecho de que la separación sea posible: si fuese imposible, todo andaría mejor. El vendedor de palomas sabe que si toma dos palomas entre las más irreconciliables (ipero macho y hembra!) y las mete en la misma jaula, acabarán por acoplarse. ¡Cuán 
seguros son los actos de Dios! Con dos gallos sería imposible, se matarían; pero un macho y una hembra deben de adaptarse; cuando sea simplemente imposible que se separen, ya veréis cómo las cosas se arreglan por sí solas (Kierkegaard, 1955: 323).

En Kierkegaard, entonces, la imposibilidad de escapar de la cárcel, por disímiles que sean los caracteres, reúne necesariamente a todos los presos. La convivencia forzosa obliga a limar asperezas. En consecuencia, y a pesar de su desgaste, la cuerda que no puede romperse acaba fortaleciéndose de modo inevitable. En su tesis, lo mismo ocurre con el matrimonio. Si un hombre y una mujer viven casados, el estado conyugal robustece el vínculo entre ellos, pues hay algo eterno en la relación conyugal: «la ceremonia nupcial es también como una corona de la eternidad... Aquí la eternidad no ha terminado con el tiempo, sino que el pacto es el comienzo de la eternidad en el tiempo» (Kierkegaard, 2010: 420).

\section{b) Matrimonio y amor}

Pero el análisis del filósofo danés sobre este tema se enfoca también en otro horizonte reflexivo. En Estética del matrimonio Kierkegaard se pregunta si el amor precede al matrimonio o si es a la inversa. Es el dilema que intenta resolver. Piensa que el amor es la substancia del matrimonio. Es el elemento primero, y es de esencia tan sutil que no puede en manera alguna soportar el contacto con la realidad. El mismo noviazgo ignora la realidad, se mueve en el vacío y en la posibilidad. Cuanto más fuera de la realidad están los enamorados, más sienten la necesidad de evadirse de la realidad del matrimonio. El noviazgo es un magnífico expediente para quienes no tienen el valor de contraer la unión.

El matrimonio no debe, pues, conducir al amor; lo presupone, por el contrario, y no como un pasado sino como un presente. Pero el matrimonio comporta un momento ético y religioso que el amor no tiene: de modo que se funda en la resignación, lo que el amor no hace (Kierkegaard, 1991: 35).

Cabe, por tanto, pensar que el matrimonio, cuando se realiza con verdadero afán de unidad, conserva el amor inicial. Según las palabras de Kierkegaard, al matrimonio le acompaña una convienente «resignación» en cuanto conlleva «un momento ético y religioso» que no se da en el amor, o no se da mientras no acabe en matrimonio. Amor sin 
matrimonio parece una evasión de la decisión a la que están llamados los novios.

Ahora bien, para Kierkegaard el solo amor romántico es inmediato porque se funda en la belleza sensible. No obstante, aun así, hay en él nobleza. Ella radica en que este amor posee una cierta conciencia de la eternidad, signo que distingue al amor de la pura voluptuosidad.

El amor romántico tiene una analogía con el orden moral en la presunta eternidad que lo ennoblece, y lo salva de la pura sensualidad. Lo sensual es, en efecto, cosa del momento. Busca una satisfacción instantánea y, cuanto más refinado, más sabe hacer del instante del goce una pequeña eternidad. La eternidad verdadera del amor, que es la verdadera moralidad, tiene por primer efecto, pues, salvarlo de lo sensible. Pero si ha de producir esa eternidad verdadera, es preciso que intervenga la voluntad (Kierkegaard, 1991: 21).

La idea presente en las líneas de Kierkegaard acerca de este punto, es que al matrimonio le es indispensable superar la sensualidad originaria de la atracción entre los enamorados, ya que así habrá también un decidido compromiso por mantener el vínculo conyugal, pese a los problemas generados por una convivencia expuesta al paso del tiempo y por un natural deterioro de los encantos exteriores del otro.

En la tesis del pensador danés, quizás uno de los principales defectos del amor romántico es que carece de reflexión. No obstante esta idea, Kierkegaard también piensa que el matrimonio no es incompatible con el amor romántico, al contrario, lo glorifica. Por lo mismo, un matrimonio sin amor anula, incluso, el amor romántico. Sin embargo, una manera de subsanar el amor romántico es el «matrimonio razonado»; aquél que en el fondo es por simple convención, y cuya posibilidad de enlace se debe a la desesperación. Es el matrimonio que se adopta por motivos exteriores y secundarios, que contradicen el sentido de la unión conyugal pura y profunda:

Lo contraen libremente personas que perdieron hace tiempo la ingenuidad de la infancia; saben que el amor propiamente dicho es una ilusión, y que su realización es, en todo caso, un pium desiderium. El punto de vista que se adopta es el de la prosa de la vida, del dinero, del rango social, etc. La unión parece moral en la medida en que ha neutralizado la faz 'sensible' del matrimonio; pero queda por saber si esa neutralización no será tan contraria a la ética como a la estética... Lo eterno que, como ya hemos visto, entra en todo matrimonio aquí en realidad no aparece, porque la razón calcula siempre en lo temporal. En suma, que una unión contraída en esas condiciones es a la vez inmoral y frágil (Kierkegaard, 1991: 25-26). 
Esta cita nos indica que casarse por razones externas y secundarias (por ejemplo, consideraciones sociales) sería una degradación del verdadero sentido moral y estético que debiese estar presente en todo matrimonio. Un matrimonio realizado por meros cálculos humanos desenfoca el núcleo de la unión conyugal, va en desmedro del más auténtico sentido de este enlace entre un hombre y una mujer.

En estas observaciones de Kierkegaard sobre la relación entre matrimonio y amor, cabe suponer que estar casado durante mucho tiempo no es motivo para la pérdida de la pasión. Ya lo señala nuestro filósofo cuando sostiene que la pasión, que es la síntesis de la libertad y de la necesidad, puede subsistir en el matrimonio. Ella tiene la seguridad de lo inmediato; pero los individuos tienen al mismo tiempo un ser religioso. Por tanto, pasión y matrimonio son compatibles. Distinto es, sin embargo, cuando una pasión desventurada lleva a los hombres a recurrir a Dios y a buscar la seguridad del matrimonio. Esto altera la pasión, aunque luego pueda ser restituida. De hecho, hay una necesidad ética de que la pasión sea eterna porque la eternidad inmersa en la pasión le otorga su moralidad. Y si los enamorados refieren su amor a Dios, ese amor lleva un sello de eternidad, lo mismo que la resolución que toman y las obligaciones que adquieren. Sea como sea, la relación conyugal requiere, eso sí, despojarse de sus propios traidores: de aquellos esposos que suspiran por un amor perdido hace tiempo y que en su pensamiento ven el matrimonio como una atadura y se rebelan contra la idea de seguir casados.

Ahora bien, el pensamiento kierkegaardiano en torno al matrimonio apunta claramente a destacar la fortaleza de este estado. No se ama más que una vez en la vida. Y para realizar esta palabra se necesita del matrimonio:

¡Qué fuerza en ese 'mío' que pronuncian los esposos! Porque la voluntad, la resolución, el buen propósito, tienen entonces un acento mucho más profundo. ¡Qué energía y qué ductilidad! Pues, ¿qué hay tan rígido como la voluntad y también tan flexible como ella? ;Qué fuerza de movimiento, en vez simplemente de ese entusiasmo confuso de vagas impulsiones! Porque el matrimonio funda su institución en el cielo, y al penetrar el deber todo el organismo de las cosas, hasta su límite, ningún obstáculo será capaz de aniquilar el amor. Deja, pues, a Don Juan la glorieta y su fronda, al caballero el cielo nocturno y sus estrellas, puesto que no ven más allá. El firmamento del matrimonio es aún más elevado (Kierkegaard, 1991: 54-55).

Mientras el soltero es, a menudo, esclavo de sus caprichos, el matrimonio libera de cierta anormalidad, así como del estancamiento de 
la rutina. El matrimonio pone un sello de solidez a las relaciones entre un hombre y una mujer.

Los pasajes de Kierkegaard referidos al matrimonio muestran este estado como una inmediatez que comporta la mediatez, una infinitud que comporta lo finito, una eternidad que comporta temporalidad. Es una condición que implica una renuncia a sí mismo, se ejerce en lo vivido, supone de un a priori, pero también de una constancia intrínseca cuya fuerza es idéntica a la resolución. Su superioridad está en la resolución. El misterio es una condición indispensable para conservar la estética del matrimonio. Se teme que una vez disipado el misterio, desaparezca el amor, pero sucede lo contrario: el amor empieza sólo cuando el misterio se ha disipado. Esta idea es digna de ser resaltada. Kierkegaard está diciendo que el conocimiento profundo del cónyuge es el mejor peldaño para acrecentar el sentimiento del amor y no la permanencia del velo que dificulta y oculta la comprensión del modo de ser del otro casado con uno.

Una de las dificultades que ha de afrontar el amor conyugal es enamorarse de otro:

El marido que tiene el valor de confiar a su mujer que ama a otra está salvado, y salva también a la esposa. Pero faltando esa franqueza, el marido pierde confianza en sí mismo: lo que busca entonces en el amor de otra, lo que induce a dejarse estar es, tanto como una verdadera inclinación por otra, el dolor de no haber resistido a tiempo. Siente que está perdido y, puesto que tal es el caso, precisa fuertes narcóticos para adormecer su conciencia (Kierkegaard, 1991: 109).

En uniones donde se practica el misterio no hay felicidad. No hay que tener secretos entre los cónyuges. En el matrimonio, en rigor, todas las dificultades son interiores. Cuando el matrimonio se halla expuesto a las tribulaciones del exterior, importa naturalmente que las interiorice.

En la óptica kierkegaardiana, el matrimonio conlleva uniformidad y esa uniformidad puede expresar belleza, cosa de la que el hombre puede enorgullecerse. Si la monotonía fuese inevitable en la vida conyugal, debería reconocerse que es preciso vencerla, o sea, preservar el amor en vez de desesperarse (bien podemos recordar que también existe el hastío en aquellos que no se han casado). Kierkegaard estima que el matrimonio está instituido para el fin más noble: la posesión duradera:

'La grandeza no es un elemento dado, sin adquirido'. Pues el instinto de conquista propio del hombre, y su ejercicio, son el elemento dado; pero el hecho y la voluntad de poseer eso es lo adquirido. Se necesita orgullo para 
conquistar y bumildad para poseer: ardor para conquistar, para poseer paciencia; para conquistar, el sustento y la bebida, y el ayuno y la plegaria para poseer (Kierkegaard, 1991: 119).

El amor romántico puede ser representado en el momento, pero no el amor conyugal, puesto que el esposo ideal no lo es sólo una vez en su vida, sino cada día. Es una de las grandezas de la vida matrimonial; el oficio que reviste en el tiempo, la dedicación que exige. La conjunción de lo particular y el todo. Pongamos nosotros una imagen: en el matrimonio el amor se teje a diario, es una convivencia hecha a fuego lento y no una llamarada ardiente y abrupta, pero que se apaga apenas se enciende. No es un fósforo consumido, sino un leño quemado que tras muchas horas todavía conserva el calor de sus brasas.

En el matrimonio el amor puede ir creciendo gradualmente, o sea, disponer del tiempo en favor de sí y no en contra a raíz de las fatigas de una relación sometida al paso de ese mismo tiempo:

El amor conyugal empieza con la posesión y reviste una historia interior. Es fiel como el amor romántico, pero con esta diferencia: el amante romántico fiel, espera, por ejemplo, quince años, y entonces llega el momento de la recompensa. Un esposo es fiel durante quince años y, sin embargo, todo ese tiempo gozó de la posesión: ha conquistado, pues, constantemente, en esa larga sucesión, una fidelidad que ya poseía. El amor conyugal comporta la pasión y también la fidelidad de ésta. Pero ese esposo ideal no podría ser representado, porque lo propio de él es el tiempo en su extensión. Al cabo de los quince años, en apariencia, no ha ido más lejos que al principio, y sin embargo conoció una vida estética intensa. Su posesión no ha sido para él una propiedad muerta: adquirió constantemente su posesión. No ha combatido leones y monstruos, sino al enemigo más peligroso: el tiempo (Kierkegaard, 1991: 124).

Tal como indica Kierkegaard en esta muy extensa cita, el tiempo es para el amor conyugal una moneda de doble cara; por un lado su enemigo, pero también la oportunidad de su victoria y de su eternidad. El amor en el matrimonio es el amor de cada día y es el amor divino, y divino porque es de cada día. Todo amor sano se elabora en el tiempo; ésa es su sustancia. Esta pretensión de perdurabilidad en el tiempo es, sin duda, uno de los sellos fundamentales del estado conyugal.

Cabe señalar que en la tesis kierkegaardiana referida al matrimonio, el deber no se muestra como enemigo del amor conyugal, puesto que no le es un extraño, sino al contrario, se le aparece como un familiar de larga data y como un confidente bien conocido por los esposos. Para Kierkegaard, cuando los esposos se aman de verdad reconocen en el 
amor conyugal una voz que los invita y empuja a la eternidad, así como una acción de la Divina Providencia que avisa de cualquier peligro que amenace la unidad matrimonial.

Antes de poner punto final a este apartado, queremos hacer una última reflexión que se apoya en la siguiente expresión de Kierkegaard:

En el paganismo había un dios del amor, pero no había dios del matrimonio; en la cristiandad, hay, si me atrevo a decirlo así, un dios del matrimonio pero no hay dios del amor. Pues el matrimonio es la expresión superior del amor (Kierkegaard, 1951b: 105).

Según nuestra interpretación, la contraposición indicada en esta cita es sumamente sugerente, al punto de diferenciar claramente lo que es el amor de lo que es el matrimonio, pero, a su vez, asumiendo que el amor quizás más fuerte entre un hombre y una mujer lleva casi indefectiblemente a la resolución matrimonial. Es difícil imaginarse un amor muy fuerte en un noviazgo eterno. Nos interesa resaltar de esta última observación el hecho de que, a la luz de las palabras de Kierkegaard, el amor pareciera fortalecerse en la medida en que termina en matrimonio. Quizás una relación amorosa que elude el matrimonio se asemeja, la imagen es nuestra, a un visitante de museo que, en vez de entrar en el mismo, anduviese todo el tiempo rondando el edificio, pero sin decidirse nunca a penetrar en su interior. Si bien no todo matrimonio es por amor, ni todo amor se corona en una boda, es evidente que un hombre y una mujer que se quieren buscan darle un respaldo «institucional» a esa relación, respaldo cuyo nombre es matrimonio.

Concluyamos este primer punto sintetizando los tres grandes argumentos de Kierkegaard en favor del matrimonio: 1. El matrimonio es el 'lugar' más natural de propagación de la especie (idea que podemos asociar también con lo mencionado por él en relación con el origen divino del matrimonio). 2. No es deseable para el hombre permanecer solo (salvo si se quiere ser célibe). 3. Forja el carácter. Nos da la impresión que de estas tres grandes razones a las que Kierkegaard alude como causas para casarse, ninguna es suficiente de por sí para optar a este estado, aunque la primera y la tercera poseen una mayor 'justificación' y peso que la segunda (si excluimos de ella la decisión por el celibato a causa de una vocación religiosa). 


\section{Razones para no casarse}

También, iqué extraña invención ésa del matrimonio! Y lo que lo hace todavía más extraño, es que pasa por ser una gestión espontánea. Empero, ninguna gestión es más decisiva; pues nada es tampoco tan autoritario, tan despótico en una vida humana, como el matrimonio... Y, sin embargo, el matrimonio no es una cosa simple, sino extremadamente complicada y equívoca. Lo mismo que la carne de tortuga sabe a toda clase de carnes, el matrimonio tiene sabor a todo; y lo mismo que la tortuga es un animal lento, también lo es el matrimonio (Kierkegaard, 1951a: 68).

Habiendo dado cuenta de lo que, a nuestro modesto entender, son algunas de las ideas esenciales dadas por Kierkegaard en favor del matrimonio, aboquémonos ahora a sus consideraciones 'en contra', por decirlo así, de la decisión de casarse. Esta 'oposición' de Kierkegaard al matrimonio exige, obviamente, determinar en qué consiste exactamente su 'rechazo' a contraer la condición de casado, rechazo que no se nos manifiesta como extremo, dado que en las páginas anteriores hemos visto algunos de los juicios de Kierkegaard 'recomendando' —el término es nuestro- casarse (aunque tampoco alcanza a ser una recomendación incondicional).

Dicho esto, adentrémonos en cuáles, según el autor danés, son los puntos 'desfavorables' del matrimonio y que pueden servir de razones para justificar la decisión de no casarse y permanecer definitivamente soltero. Nuestro pensador en cuestión sostiene lo siguiente:

Lo que hay que hacer, en segundo lugar, es evitar a todo trance el matrimonio. Los esposos se prometen entre sí un amor eterno. Esto es demasiado fácil y no significa gran cosa, ya que si se logra cumplir tales promesas en el tiempo, no habría mayor dificultad en cumplirlas en la eternidad. De ahí que lo mejor sería que las partes interesadas, en vez de prometerse un amor para toda la eternidad, dijesen: hasta Pascuas o hasta la primavera próxima. Esto ya sería hablar con cierta cordura, pues habrían dicho algo que quizás cumplieran. ¿Qué es lo que pasa a fin de cuentas con el matrimonio? Apenas ha transcurrido un poco de tiempo cuando una de las partes advierte que aquello no marcha bien; entonces la otra se lamenta y ponen el grito en el cielo, diciendo: jtraición, traición! Poco después la otra parte se encuentra en la misma situación en que se encontró la primera, y así se llega a establecer una cierta neutralidad, puesto que dos traiciones recíprocas crean una situación y contentamiento mutuos (Kierkegaard, 2005: 41). 
Si bien la cita es larga, no podíamos omitirla. Espiguemos qué es lo que Kierkegaard quiere señalarnos en este pasaje. De acuerdo a nuestro entender, en las líneas precedentes se intenta desincentivar el matrimonio mostrando que habría una imposibilidad natural de prometerse en esta vida un amor eterno. Lo mejor para los esposos sería más bien prometerse el amor sólo por un período determinado o hasta una fecha $\mathrm{x}$ más o menos cercana en el tiempo. Según sus palabras, habría cierta imprudencia en prometer demasiado en el tiempo, puesto que lo más cauto o lo más cuerdo es decirle a otro que la decisión fiel será cumplida hasta una fecha próxima (luego puede renovar la decisión). En las materias importantes de su vida el ser humano necesita ser precavido. Una de esas materias es, por cierto, la del matrimonio y, en consecuencia, toda la fidelidad conyugal requiere un trabajo diario que, en vez de aventurar compromisos eternos, más bien tiene que construirse lentamente y con vistas a un plazo próximo, a fin de que perdurabilidad esté garantizada en el tiempo respecto al peldaño que sigue antes que aludir a la cima saltándose los escalones intermedios y más inmediatos.

A nuestro entender, en todo caso, lo dicho en el párrafo precedente 'funciona' no tanto como un argumento contra el matrimonio en sí, sino contra aquellas promesas de amor eterno asociadas al matrimonio y que Kierkegaard estima erradas, pues lo pertinente para él sería más bien hacer promesas apuntando a plazos menos extensos en el orden temporal. Sin embargo, la idea de Kierkegaard es clara: un equívoco habitual de los que se casan y que es desfavorable al matrimonio es hacer promesas de fidelidad 'desmedidas' —el término es nuestro—, promesas que, al fin y al cabo, no son de por sí definitivas, ya que está sometidas a muchas pruebas y requieren, por ende, ir siendo renovadas por cada esposo en más de una ocasión y a lo largo del tiempo.

Veamos ahora más razones de Kierkegaard opuestas al enlace conyugal. En uno de sus escritos, Kierkegaard menciona la siguiente idea:

Siempre habrá que andar con cuidado para no contraer ninguna relación vital que nos multiplique y nos haga perder nuestra independencia... Es verdad que se dice que lo esposos se convierten en una sola cosa, pero este modo de hablar es muy enigmático y místico. Cuando uno se ha multiplicado de esta manera, ya no goza de su libertad primitiva, ni puede andar de acá para allá según su capricho, o hacer las maletas y marcharse al extranjero. Si se tiene mujer es difícil hacerlo, si la mujer espera tener un hijo, entonces es todavía más difícil, pero si se tiene mujer e hijos, la cosa es imposible (Kierkegaard, 2005: 43-44). 
Aquí hay otro punto muy concreto en contra del matrimonio: la privación de la libertad anterior de la que gozaba una persona, libertad que se ve restringida hasta límites casi extremos cuando se contrae matrimonio y, más aún, si esa persona tiene hijos.

¿Qué intenta Kierkegaard mostrarnos en esta última cita? A lo mejor, es lo que pensamos, quiere ahondar en los 'encadenamientos' que suelen contraer quienes se casan. Casarse, tal parece ser su reflexión, quita libertad e independencia (está refiriéndose sobre todo al varón). Quien se casa se caza a sí mismo, por decirlo así, con las obligaciones propias e irrenunciables del estado matrimonial. En este sentido el matrimonio es un estado vital que tiende a restringir antes que alimentar las libertades de los que alcanzan ese estado. El que está en la situación de marido, y sobre todo en la de marido y padre, no puede disponer de su vida con la misma libertad que lo hacía en su época anterior a su matrimonio. Usando una imagen nuestra, casarse es obligarse a mover la rueda de la rutina quizás en mayor medida que si no estuviese en esa condición. Dicho de otra manera, quien vive el enlace conyugal vive también sujeto a una cuerda de responsabilidad imposible de resquebrajar.

Una tercera razón de Kierkegaard contraria al vínculo nupcial es la que se desprende de uno de sus escritos más breves:

La amistad es de suyo peligrosa, el matrimonio lo es aún más. Esto segundo es fácil de explicar, por cuanto la mujer siempre será la ruina del hombre desde el momento en que éste mantenga una relación vitalicia con ella. Imaginad a un hombre joven, ardiente como un caballo árabe; en cuanto se case, estará perdido. La mujer al principio es engreída, después se hace débil, más tarde se desmaya, y entonces se desmaya el marido y, naturalmente, toda la familia. El amor de una mujer no es más que fingimiento y debilidad (Kierkegaard, 2005: 44-45).

En este párrafo el filósofo danés sostiene algunas expresiones que pueden sonar incluso controvertidas, pues indica que cualquier relación perdurable entre un hombre y una mujer supone una 'ruina' para el varón y, además, apunta a que no hay sinceridad, sino estrategia, en el amor femenino hacia el hombre. El amor de la mujer hacia el hombre sería, por consiguiente, un asunto de táctica y de conveniencia, puesto que, así lo da a entender, a la mujer le conviene la condición de casada, tal como al hombre le es más favorable conservar su condición de soltero.

Una cuarta afirmación opuesta al enlace nupcial es esta: 
Amor y matrimonio son en el fondo un corroborante más profundo del amor propio; uno se vuelve doblemente egoísta; por esto los esposos se sienten tan contentos, tan prósperos para la vida vegetativa, porque el puro amor no está hecho para la existencia terrenal como el egoísmo. El solitario, por lo mismo, carece de egoísmo, los esposos lo expresan de él: 'Es un egoísta'; porque los esposos parten del principio de que el matrimonio es amor (Kierkegaard, 1955: 198).

En consecuencia, esta cita lo que parece decirnos es que los novios no se casan tanto por amor al otro, sino más bien por amor a sí mismos. $\mathrm{Y}$ en este sentido, entonces, casarse respondería no a un acto de generosidad, sino más bien de egoísmo. Según esta última cita, quien se casa lo hace por amor a sí mismo y no por amor a otro. Y, al contrario de lo que estima el juicio social más común, serían egoístas los casados más que los solteros.

Una quinta idea en la que Kierkegaard manifiesta una oposición a la idea de casarse es su juicio acerca de que el matrimonio trae ciertas derrotas que los casados ocultan a los demás: «Se ponen de acuerdo en mentir, afirmando que el matrimonio es la verdadera felicidad, iy que ellos son particularmente felices!» (Kierkegaard, 1955: 406). ¿Qué quiere decirnos Kierkegaard con esto? Según su mismo Diario intimo hay una propensión del ser humano a esconder sus tribulaciones ante los demás, en particular las tribulaciones referidas a las dificultades conyugales. Esta tendencia humana a poner buena cara al mal tiempo es todavía mayor en el caso de la mujer que, según el filósofo danés, «posee un innato virtuosismo para la mentira y en el fondo no es feliz si no puede poner su pizca de embuste en toda cosa. Como que podemos estar seguros $a$ priori que donde interviene la mujer, interviene la mentira... La mujer está en poder de una determinación natural que muy hábilmente se sirve de ella para enervar al hombre» (Kierkegaard, 1955: 406). Si tomamos al pie de la letra las reflexiones de Kierkegaard sobre este asunto, la natural disposición humana a presentar ante los demás una situación propia mejor que la real también acontece respecto del propio matrimonio. Las dificultades matrimoniales sueñen mantenerse puertas adentro y no darse a conocer puertas afuera. Comúnmente nadie expone en demasía a los otros aquellos nubarrones que sobrevuelan su condición nupcial. Lo bueno y lo malo de la intimidad conyugal sigue siendo todavía uno de los espacios más privados del ser humano.

Conviene tener presente que si bien Kierkegaard valora la unidad que el matrimonio genera entre los esposos, es una unidad quizás no tan radical como algunos suelen hacerlo ver: «El matrimonio representa la unidad en el aspecto de la sensibilidad, no la unidad en el espíritu ni en la 
verdad; porque el Génesis dice que 'el hombre y la mujer serán una sola carne’ (Génesis, 2-24)» (Kierkegaard, 1955: 72-73). En concordancia con lo dice aquí, casarse, para el filósofo danés, es la unión en lo sensible, pero no necesariamente en lo espiritual, con lo cual la unidad sería en relación a lo más externo del ser humano, pero no a lo más interno.

Como ya habíamos señalado en la primera página de este artículo, Kierkegaard da algunas razones de por qué él no debía casarse (las que podemos considerar como una sexta idea de su oposición al matrimonio, pero en este caso únicamente alusivas sólo a él): «Pero para mí era demasiado serio el pensamiento de que no podría realizar el matrimonio; también había algo de infantil su presunción» (Kierkegaard, 1955: 297). Tal como señala aquí, confiesa pensar con seriedad y al mismo tiempo con algo de presunción infantil, que él no podría realmente casarse. Como admite o reconoce en la cita siguiente, él tenía algo de 'incorpóreo' en su modo de ser y una mujer — en este caso Regina Olsen - al cabo de poco tiempo se habría 'acongojado', entristecido quizás en grado sumo (recordemos que Kierkegaard temía 'transmitirle' su propia melancolía), situación, por cierto, sumamente inconveniente para el éxito de cualquier matrimonio:

Admitamos que me hubiera casado con ella. ¿Qué habría sucedido? En menos de un año se hubiera acongojado. Hay en mí (en ello consiste el lado bueno y el malo de mi naturaleza) algo de incorpóreo, algo que hace que nadie pueda enfrentarse conmigo cuando de compartir la vida cotidiana se trata, y entablar de este modo una relación real... Yo era demasiado pesado para ella y ella demasiado pesada para mí (Kierkegaard, 1955: 300).

Respecto de su misma disposición hacia el matrimonio, Kierkegaard asume que este estado le parecía a él una 'traba'. Da la impresión que Kierkegaard, pudiendo escoger, prefiere lo que él mismo llama 'relación fraternal' antes que una relación matrimonial. Mientras la primera puede darle una gran alegría, la segunda más bien le plantea miedos y riesgos anímicos tanto para él como para su eventual esposa (otra vez Regina Olsen):

Si Dios le inspirara el pedido de una entrevista conmigo, sí... en ese caso me arriesgaría. Me daría placer: esto es verdad, pero sólo así me atrevería a correr el riesgo. Nuestra relación sería entonces perfecta, pues el matrimonio es mi traba; una relación fraternal con ella me daría una grande, muy grande alegría (Kierkegaard, 1955: 387-388). 
Como punto final a este artículo, nos cabe indicar que el pensamiento de Kierkegaard en torno al matrimonio también lo comprende como una vocación. Pero, al igual que toda otra vocación, Kierkegaard hace bien en señalar que ellas no son abstractas. Descubrir en uno una determinada vocación (lo que también se aplica al matrimonio) no supone saber de antemano con quién - si fuese el caso- ha de realizarse esa vocación. Digámoslo de una manera simple: saber que hay que casarse no es saber con quién hay que casarse. La persona a escoger es una segunda tarea que surge tras ver en uno mismo el afán por contraer matrimonio:

No desconocerá la importancia de la diferencia, puesto que, desde que ha comprendido que no existe ninguna vocación abstracta, sino que todo hombre posee su vocación, comprenderá que no existe ningún matrimonio abstracto. La ética le dice simplemente que debe casarse, no puede decirle con quién. La ética le muestra lo general dentro de la diferencia y él ve la diferencia dentro de lo general (Kierkegaard, 1959: 199).

\section{Conclusión}

En este artículo hemos esbozado las principales ideas de Kierkegaard sobre el matrimonio, tanto en sus consideraciones que recomienda la vida de casado como en aquellas en las que simplemente advierte de los riesgos y puntos en contra de la vida conyugal. Sobre este tema, por tanto, hay un Kierkegaard con dos posturas contrapuestas, la del firme defensor del estado matrimonial y la del hombre que más bien sugiere (tanto a sí mismo como a otros) abstenerse de contraer la condición de casado. A modo de recapitulación, enumeremos sus argumentos en pro y en contra de esta decisión.

En cuanto a sus argumentos favorables al matrimonio, podemos indicar que los principales son los siguientes: 1 . Lo ve como una condición deseable y recomendable para el ser humano, puesto que atribuye su origen a Dios. 2. Es el estado que considera más propiamente ético para engendrar hijos. 3. Fortalece el carácter de los esposos. 4. Impide la angustia de la soledad. 5. Representa incluso un cierto 'ideal' de vida para el mismo Kierkegaard, puesto que mostró arrepentimiento por no haberse casado con su novia y porque escribió sobre el matrimonio asumiendo el papel de un hombre casado que entiende que todo tipo de sentimientos, inclusos aquellos de naturaleza religiosa, se llevan mejor cuando se comparten con la propia mujer. 
En cuanto a las objeciones más importantes de Kierkegaard respecto al matrimonio, ellas pueden sintetizarse en una primera de índole religiosa, otras de índole práctica y una última de índole personal. Mencionemos cada una de ellas: 1. El matrimonio tendría una importancia desmedida y es incompatible con lo que Kierkegaard llama 'existencias religiosas más decisivas'. Hay ciertas vidas - la religiosa, por ejemplo-, que llevan en sí la exigencia de renunciar a la pretensión de casarse. 2. Sería beneficioso no contraer matrimonio (al hombre más que a la mujer) porque el que se casa pierde en gran medida su libertad. 3. Un equívoco en que suelen caer los esposos - y que para Kierkegaard también se opone al propósito matrimonial - es prometerse amor eterno, siendo que les sería mucho más apropiado formular esa promesa respecto de plazos más inmediatos y próximos. 4. Quienes se casan con frecuencia encubren ante los otros las dificultades, los pesares y los contratiempos propios de la vida conyugal, y revisten al matrimonio de una apariencia idílica incompatible con la realidad. 5. Nuestro filósofo no deja fuera razones de carácter personal que le hacían recomendable en su propio caso evitar a toda costa el enlace conyugal. Estas razones se resumen más que nada en una sola idea: 'melancolía'. Su misma naturaleza melancólica era para él un poderoso obstáculo contra sus pretensiones matrimoniales (alguna vez las tuvo), ya que temía que su mujer 'heredara' (pensamos que también sus posibles hijos podrían haber recibido esta 'herencia') este rasgo suyo tan incompatible con la felicidad que se busca en el matrimonio.

Dicho todo lo anterior, cabe concluir que los argumentos de Kierkegaard sobre el matrimonio en un sentido y en otro lo muestran como un autor contradictorio en este tema. Aun así, tendemos a pensar que Kierkegaard tenía un juicio más bien favorable que desfavorable en relación con la condición de casado. Incluso más, sus continuas reflexiones y referencias a Regina Olsen en sus distintos escritos nos inducen a suponer que el filósofo danés lamentó siempre no haberse casado con ella. De haberlo hecho, quizás habría sido un hombre más feliz, aunque a lo mejor no hubiese alcanzado nunca tanta fecundidad como pensador de la intimidad.

\section{REFERENCIAS}

-Jolivet, R. (1950). Introducción a Kierkegaard. Madrid: Editorial Gredos.

-Kierkegaard, S. (1950). Estética y ética en la formación de la personalidad. Buenos Aires: Editorial Nova. 
-Kierkegaard, S. (1951a). In vino veritas. En Etapas en el camino de la vida. Buenos Aires: Santiago Rueda-Editor.

-Kierkegaard, S. (1951b). Palabras sobre el matrimonio. En Etapas en el camino de la vida. Buenos Aires: Santiago Rueda-Editor.

-Kierkegaard, S. (1955). Diario intimo. Buenos Aires: Santiago Rueda-Editor.

-Kierkegaard, S. (1959). Estética y ética. Buenos Aires: Editorial Nova.

-Kierkegaard, S. (1973). Diario de un seductor. Barcelona: Ediciones 29.

-Kierkegaard, S. (1991). Estética del matrimonio. Buenos Aires: Editorial Leviatán.

-Kierkegaard, S. (1999). Diapsálmata. Santiago: Be-uve-dráis Editores.

-Kierkegaard, S. (2005). La rotación de los cultivos. Ensayo de una ciencia del buen sentido social. Santiago: Be-uve-dráis Editores.

-Kierkegaard, S. (2010). En ocasión de una boda. En Discursos edificantes. Tres discursos para ocasiones supuestas. Madrid: Editorial Trotta.

-Wahl, J. (1956). Kierkegaard. Buenos Aires: Ediciones Losange.

Sumario: 1. Razones para casarse; 2. Razones para no casarse; Conclusión; Referencias. 